\title{
ANALISIS KINERJA REDISTRIBUSI ROUTING PROTOKOL DINAMIK (Studi Kasus : RIP, EIGRP, IS-IS)
}

\author{
Chairul Mukmin1, Edi Surya Negara² \\ 1,2Fakultas Ilmu Komputer, Universitas Bina Darma Palembang \\ Jl. Jend. A Yani No.3, 0711-515582 \\ chairul.mukmin@binadarma.ac.id¹, e.s.negara@binadarma.ac.id ${ }^{2}$
}

\begin{abstract}
Each routing protocol has different algorithms and metrics in determining the best path on a network. Differences 1) Applications that only run on routing protocols 2) hardware from various vendors 3) Networks with different routing areas or domains. Some aspects that become a reference for some routing protocols that are issued from data sent and lost in the process of sending data (packet loss), speed in sending data (delay), as well as the ability of some routing protocols in choosing the closest distance when sending data transmission packets. Routing protocol characteristics. This study studies analyzing routing redistribution in dynamic routing protocols, in order to find out which routing protocols perform better in networks that are different from autonomous systems (AS) with measurement parameters of Throughput, Delay and Packet Loss.
\end{abstract}

Keywords : EIGRP, IS-IS, Redistribution Routing, RIP, Routing Protocol

\section{Abstrak}

Setiap protokol routing memiliki algoritma dan metrik yang berbeda-beda dalam menentukan jalur terbaik pada sebuah jaringan. Perbedaan karakteristik tersebut menimbulkan beberapa masalah 1)aplikasi yang hanya berjalan pada protokol routing tertentu 2)hardware dari berbagai vendor 3)Jaringan dengan area atau domain routing berbeda. Beberapa aspek yang menjadi acuan suatu protokol routing diantaranya dari segi data yang terkirim dan hilang dalam proses pengiriman data (packet loss), kecepatan dalam pengiriman data (delay), juga kemampuan suatu protokol routing dalam memilih jarak terdekat bahkan jalur terbaik dalam pengiriman paket data. Perbedaan karakteristik protokol routing tersebut tersebut dapat diselesaikan dengan cara menggunakan redistribusi routing. Penelitian ini bertujuan menganalisis perbandingan redistribusi routing pada protokol routing dinamik, guna mencari tahu protokol routing mana yang lebih baik kinerjanya dalam jaringan yang berbeda autonomous system (AS) dengan parameter pengukuran Throughput, Delay dan Packet Loss.

Kata Kunci : EIGRP, IS-IS, Redistribusi Routing, RIP, Protokol Routing

\section{PENDAHULUAN}

Jaringan Komputer adalah kumpulan koneksi antara 2 komputer atau lebih yang terhubung dengan transmisi kabel atau tanpa kabel (wireless)[1]. Dalam 
menghubungkan jaringan local area network (LAN) yang satu dengan jaringan LAN yang lain tentu menggunakan alat bantu yang disebut router. Router adalah salah satu komponen pada jaringan komputer yang mampu melewatkan data melalui sebuah jaringan atau internet menuju sasarannya, melalui sebuah proses yang dikenal sebagal routing[2]. Didalam router itu sendiri ada yang protokol routing. Protocol routing merupakan salah satu komponen terpenting pada jaringan TCP/IP. Dengan dinamik routing maka mekanisme routing dilakukan secara dinamis dengan menentukan jarak terpendek secara cepat dan akurat antara peralatan pengirim dan penerima[3].

Adapun klasifikasi prokotol routing versi cisco, Routing Information Protocol (RIP), Interior Gateway Routing Protocol (IGRP), Enhanced Interior Gateway Routing Protocol (EIGRP), Open Shortest Path First (OSPF), Intermediate System to Intermediate System (IS-IS), Bolder Gateway Protocol (BGP)[4]. Setiap protokol routing memiliki algoritma dan metrik yang berbeda-beda dalam menentukan jalur terbaik pada sebuah jaringan.

Perbedaan karakteristik tersebut menimbulkan masalah 1)aplikasi yang hanya bisa berjalan pada protokol routing tertentu 2)hardware dari berbagai vendor 3)jaringan dengan area atau domain routing berbeda[5]. Beberapa aspek yang menjadi acuan suatu kualitas jaringan diantaranya dari segi data yang terkirim dan data yang hilang dalam proses pengiriman data (packet loss), kecepatan dalam pengiriman data (delay), juga kemampuan suatu protokol routing dalam memilih jarak terdekat bahkan jalur terbaik jika terjadinya kesalahan pada suatu jalur dalam pengiriman paket data.

Perbedaan karakteristik pada setiap protokol routing tersebut dapat diselesaikan dengan cara menggunakan redistribusi routing. Redistribution adalah metode routing yang digunakan untuk meredistribusikan atau meneruskan suatu routing ke routing yang lain agar dapat saling menukarkan atau men-advertise routing table masing-masing[6]. Redistribusi routing dapat menerima berbagai kompleksitas protokol routing dan dapat membentuk tabel routing yang lebih kompleks, kadang pemilihan jalur menggunakan informasi tabel redistribusi routing tidak dapat optimal karena pengetahuan dan cara konfigurasi yang tidak sesuai dengan yang dibutuhkan. Pada prinsipnya redistribusi routing akan mendistribusikan protokol routing yang satu kemudian diteruskan kembali ke protokol routing yang lainnya melalui router terminal atau router yang menjadi penghubung dalam satu autonomous system (AS) dengan autonomous system (AS) lainnya. Autonomous system (AS) adalah sekelompok jaringan yang dikelola oleh satu atau lebih operator di bawah kebijakan routing yang terdefinisi dengan baik[7].

Perbedaan karakteristik protokol routing ini tentu akan mempengaruhi kinerja pada suatu jaringan. Tujuan penelitian ini untuk menganalisis perbandingan redistribusi routing pada protokol routing dinamik RIP, EIGRP, IS-IS, guna mencari tahu kolaborasi protokol routing mana yang lebih baik dalam jaringan redistribusi routing dengan parameter pengukuran throughput, delay dan packet loss.

Berikut ini merupakan penelitian terkait "Comparison Route Redistribution on Dynamic Routing Protocol Case Study EIGRP into OSPF and EIGRP into IS-IS" keterkaitan dengan penelitian sebelumnya sama-sama membahas tentang 
redistribusi routing, yang menjadi perbedaan dengan penelitian sekarang yaitu dengan menambahkan variabel baru dengan skenario pengukuran yang berbeda yaitu protokol routing RIP redistribui EIGRP, RIP redistribusi IS-IS dan EIGRP redistribusi IS-IS [5]. "Performance Analysis and Redistribution Among RIPv2, EIGRP, and OSPF Routing Protocol" keterkaitan dengan penelitian sebelumnya sama-sama membahas tentang redistribusi routing, yang menjadi perbedaan dengan penelitian sebelumnya yaitu interface yang digunakan masih menggunakan interface serial untuk menghubungi antar router, topologi, dan metrik yang gunakan misalnya jumlah bandwitdh pada setiap jalurnya[8]. "Performance Evaluation of Routing Protocols RIPng, OPSFv3, and EGIRP in an Ipv6 Network" Keterkaitan dengan penelitian sebelumnya masih sama membahas tentang redistribusi routing, hanya saja perbedaan yang menonjol dimana pada penelitian sebelumnya dilakukan pada protokol routing untuk protokol jaringan IPv6, dengan menambahkan variabel pengukuran $Q o S$ yaitu jilter, pada protokol pengujian untuk menghubungan antar router semuanya menggunakan interface serial, dan IOS Cisco 3725 Series[9]. "Performance Evaluation of Routing Protocol RIPv2, OSPF, EIGRP with BGP". Keterkaitan dengan penelitian sebelumnya masih sama membahas tentang redistribusi routing, yang menjadi perbedaan dengan penelitian sebelumnya dimana protokol pengujian melibatkan antara protokol routing Exterior Routing Protokol yaitu Bolder Gateway Protokol (BGP), diketahui bahwa BGP biasanya digunakan untuk menghubungan jaringan yang autonomous system nya berbeda[10].

\section{METODOLOGI PENELITIAN}

\subsection{Metode Simulasi}

Penelitian ini menggunakan metodologi simulasi yang terdiri dari beberapa tahapan :

\section{a. Problem Formulation}

Komplesitas dalam jaringan tidak bisa dihindari, hal ini mendorong administrator untuk selalu mengikuti perkembangan teknologi guna dapat mempertahankan kebutuhan penguna akan jaringan internet. Berdasarkan latar belakang banyak hal yang dapat mempengaruhi kualitas suatu jaringan untuk itu penelitian ini bertujuan menganalisis kinerja jaringan dengan variabel Throughput, Delay dan Packet Loss.

\section{b. Conceptual Model}

Skenario dibuat dengan memanfaatkan Graphical Network Simulator 3 (GNS3). Adapun dalam protokol pengujian protokol routing yang digunakan yaitu protokol routing interior routing protocol dengan skema kolaborasi protokol routing RIPv2 redistribusi EIGRP, RIP Redistribusi IS-IS dan EIGRP redistribusi IS-IS. Desain topologi melibatkan 12 Host dengan tujuan membebani lalu lintas jaringan. Adapun alat yang digunakan dalam skenario pengujian :
1) Cisco Router 7200 Series
2) 12 Virtual PC (VPCS) yang bertindak sebagai Host
3) 8 Switch 
4) 36 Koneksi dengan Interface Gigabyte

5) Server (Windows XP) di VirtualBox

6) Client (Windows XP) di VirtualBox (ICMP ke Server : size 60000 bytes)

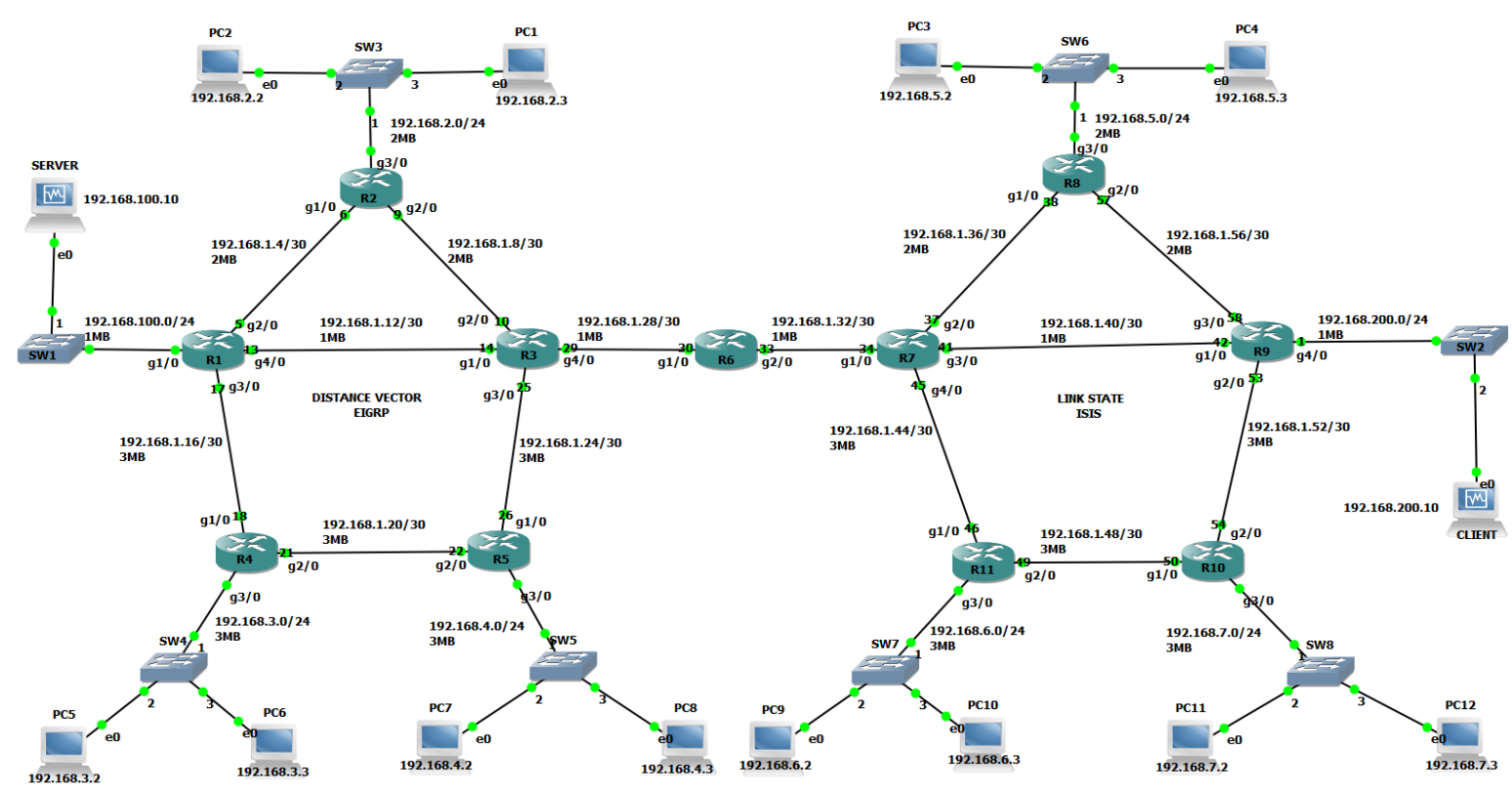

Gambar 1. Rancangan Topologi Jaringan

\begin{tabular}{|c||c|c||c|c|c||c||}
\hline \hline \multicolumn{1}{|c|}{ Needed Size } & Allocated Size & \multicolumn{1}{c|}{ Address } & Mask & Dec Mask & Assignable Range & Broadcast \\
\hline 2 & 2 & 192.168 .1 .4 & $/ 30$ & 255.255 .255 .252 & $192.168 .1 .5-192.168 .1 .6$ & 192.168 .1 .7 \\
\hline \hline 2 & 2 & 192.168 .1 .8 & 130 & 255.255 .255 .252 & $192.168 .1 .9-192.168 .1 .10$ & 192.168 .1 .11 \\
\hline \hline 2 & 2 & 192.168 .1 .12 & 130 & 255.255 .255 .252 & $192.168 .1 .13-192.168 .1 .14$ & 192.168 .1 .15 \\
\hline \hline 2 & 2 & 192.168 .1 .16 & 130 & 255.255 .255 .252 & $192.168 .1 .17-192.168 .1 .18$ & 192.168 .1 .19 \\
\hline \hline 2 & 2 & 192.168 .1 .20 & 130 & 255.255 .255 .252 & $192.168 .1 .21-192.168 .1 .22$ & 192.168 .1 .23 \\
\hline \hline 2 & 2 & 192.168 .1 .24 & 130 & 255.255 .255 .252 & $192.168 .1 .25-192.168 .1 .26$ & 192.168 .1 .27 \\
\hline \hline 2 & 2 & 192.168 .1 .28 & 130 & 255.255 .255 .252 & $192.168 .1 .29-192.168 .1 .30$ & 192.168 .1 .31 \\
\hline \hline 2 & 2 & 192.168 .1 .32 & 130 & 255.255 .255 .252 & $192.168 .1 .33-192.168 .1 .34$ & 192.168 .1 .35 \\
\hline \hline 2 & 2 & 192.168 .1 .36 & 130 & 255.255 .255 .252 & $192.168 .1 .37-192.168 .1 .38$ & 192.168 .1 .39 \\
\hline \hline 2 & 2 & 192.168 .1 .40 & 130 & 255.255 .255 .252 & $192.168 .1 .41-192.168 .1 .42$ & 192.168 .1 .43 \\
\hline \hline 2 & 2 & 192.168 .1 .44 & 130 & 255.255 .255 .252 & $192.168 .1 .45-192.168 .1 .46$ & 192.168 .1 .47 \\
\hline \hline 2 & 2 & 192.168 .1 .48 & 130 & 255.255 .255 .252 & $192.168 .1 .49-192.168 .1 .50$ & 192.168 .1 .51 \\
\hline \hline 2 & 2 & 192.168 .1 .52 & 130 & 255.255 .255 .252 & $192.168 .1 .53-192.168 .1 .54$ & 192.168 .1 .55 \\
\hline \hline 2 & 192.168 .1 .56 & 130 & 255.255 .255 .252 & $192.168 .1 .57-192.168 .1 .58$ & 192.168 .1 .59 \\
\hline
\end{tabular}

Gambar 2. Pengalamatan IP Address Pada Topologi Jaringan Antar Router

c. Input and Output Packet

1) Input

a) Node

Node merupakan jumlah loncatan router ke router yang lainnya. Semakin banyaknya jumlah node tentu hal ini akan mempengaruhi kinerja dari jaringan yang akan di analisis. Jumlah router yang digunakan dalam penelitian sebanyak 11 router. 
b) Bandwidth adalah suatu nilai konsumsi transfer data yang dihitung dalam bit/detik atau yang biasanya disebut dengan bit per second (bps), antara server dan client dalam waktu tertentu[11]. Dalam protokol penelitian bandwidth dibuat bervariasi pada setiap jalurnya hal ini bertujuan untuk membuktikan karakteristik masing-masing protokol routing dalam menentukan paket ICMP yang dikirim harus lewat jalur yang mana. Dengan ketentuan bandwidth 4 Hop/Node $=1 \mathrm{Mb} / \mathrm{s}, 6$ Hop $/$ Node $=2 \mathrm{Mb} / \mathrm{s}, 8 \mathrm{Hop} / \mathrm{Node}=3 \mathrm{Mb} / \mathrm{s}$.

c) Windows Size

ICMP singkatan dari Internet Control Message Protocol yang bertugas mengirimkan pesan-pesan kesalahan dan kondisi lain yang memerlukan perhatian khusus[12]. Dalam pengujian paket ICMP dikirim sebesar 60000 bytes dari client ke server, sedangkan 12 Host lainnya berfungsi membuat trafik jaringan menjadi padat.

\section{2) Output}

Quality of Service (QoS) didefinisikan sebagai ukuran seberapa baik jaringan dan upaya untuk menentukan karakteristik dan sifat layanan[13]. Variabel yang menjadi pengukuran dalam penelitian ini yaitu Troughput, Delay dan Packet Loss.

Troughput adalah kecepatan (rate) transfer data efektif, yang diukur dalam bps, jumlah total kedatangan paket yang sukses yang diamati pada destination selama interval waktu tertentu dibagi oleh durasi interval waktu tersebut[14].

Tabel 1. Standarisasi Throughput versi TIPHON

\begin{tabular}{ccc}
\hline Kategori Degradasi & Throughput & Indeks \\
\hline Sangat Bagus & $100 \%$ & 4 \\
Bagus & $75 \%$ & 3 \\
Sedang & $50 \%$ & 2 \\
Jelek & $<25 \%$ & 1 \\
\hline
\end{tabular}

Delay adalah variasi kedatangan paket, hal ini diakibatkan oleh variasivariasi dalam panjang antrian, dalam waktu pengolahan data, dan juga dalam waktu penghimpunan ulang paket-paket di akhir perjalanan[14].

Tabel 2. Standarisasi Delay versi TIPHON

\begin{tabular}{ccc}
\hline Kategori Degradasi & Delay/Latency & Indeks \\
\hline Sangat Bagus & $<150 \mathrm{~ms}$ & 4 \\
Bagus & $150 \mathrm{s.d} 300 \mathrm{~ms}$ & 3 \\
Sedang & $300 \mathrm{s.d} 450 \mathrm{~ms}$ & 2 \\
Jelek & $>450 \mathrm{~ms}$ & 1 \\
\hline
\end{tabular}


Packet Loss adalah suatu parameter yang menggambarkan suatu kondisi yang menunjukan jumlah total paket yang hilang[14].

Tabel 3. Standarisasi Packet Loss versi TIPHON

\begin{tabular}{ccc}
\hline Kategori Degradasi & Packet Loss & Indeks \\
\hline Sangat Bagus & $0 \%$ & 4 \\
Bagus & $3 \%$ & 3 \\
Sedang & $15 \%$ & 2 \\
Jelek & 25 & 1 \\
\hline
\end{tabular}

\section{d. Modelling}

Skenario pemodelan ini dengan merancang sebuah topologi yang disimulasikan di Graphical Network Simulator 3 (GNS3). Topologi inilah yang nanti akan digunakan dalam pengujian, dengan skema pengujian kolaborasi protokol routing RIPv2 redistribusi EIGRP, RIP Redistribusi IS-IS dan EIGRP redistribusi IS-IS. Parameter yang pengukuran dalam simulasi yaitu Throughput, Delay dan Packet Loss.

\section{e. Simulation}

Pada penelitian ini simulasi skenario menggunakan Graphical Network Simulator 3 (GNS3) versi 2.1.4 yang berjalan pada Windows 10 Pro 64-Bit. Router IOS Cisco 7200 Series for GNS3, VirtualBox Version 6.0.10 r132072 untuk menjalankan Windows XP yang berperan sebagai Server dan Client, Axence netTools 5.0.1.13719 digunakan sebagai tool pengukuran dan pengiriman paket ICMP dari client ke server. Axence netTools dipasang di host yang berperan sebagai Client.

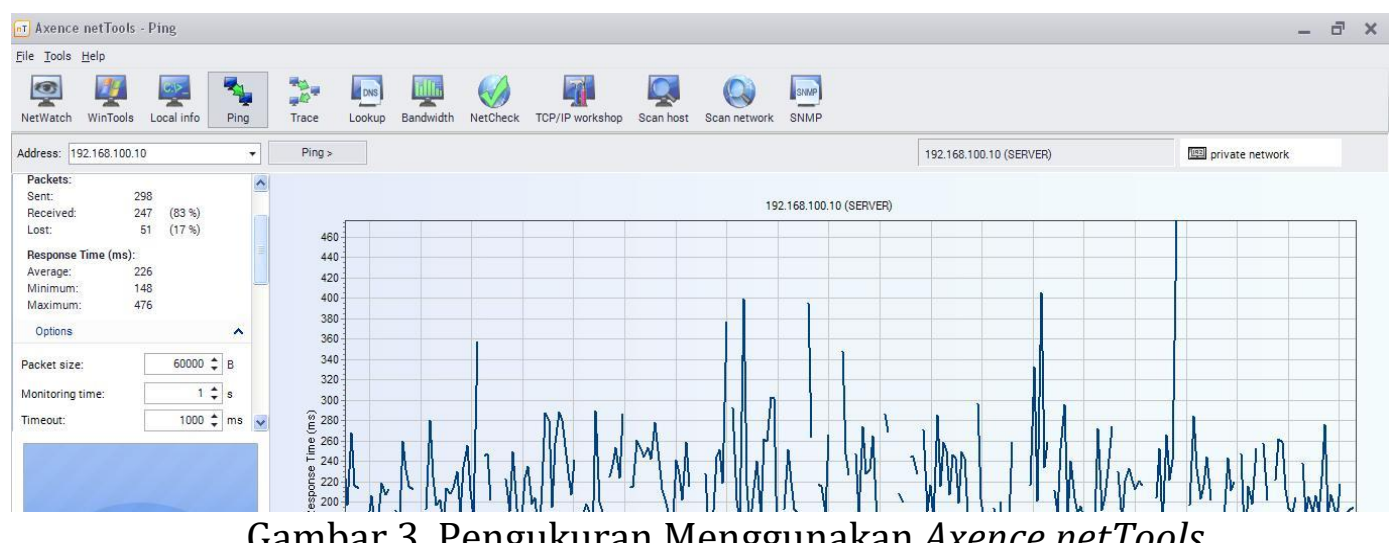

Gambar 3. Pengukuran Menggunakan Axence netTools 


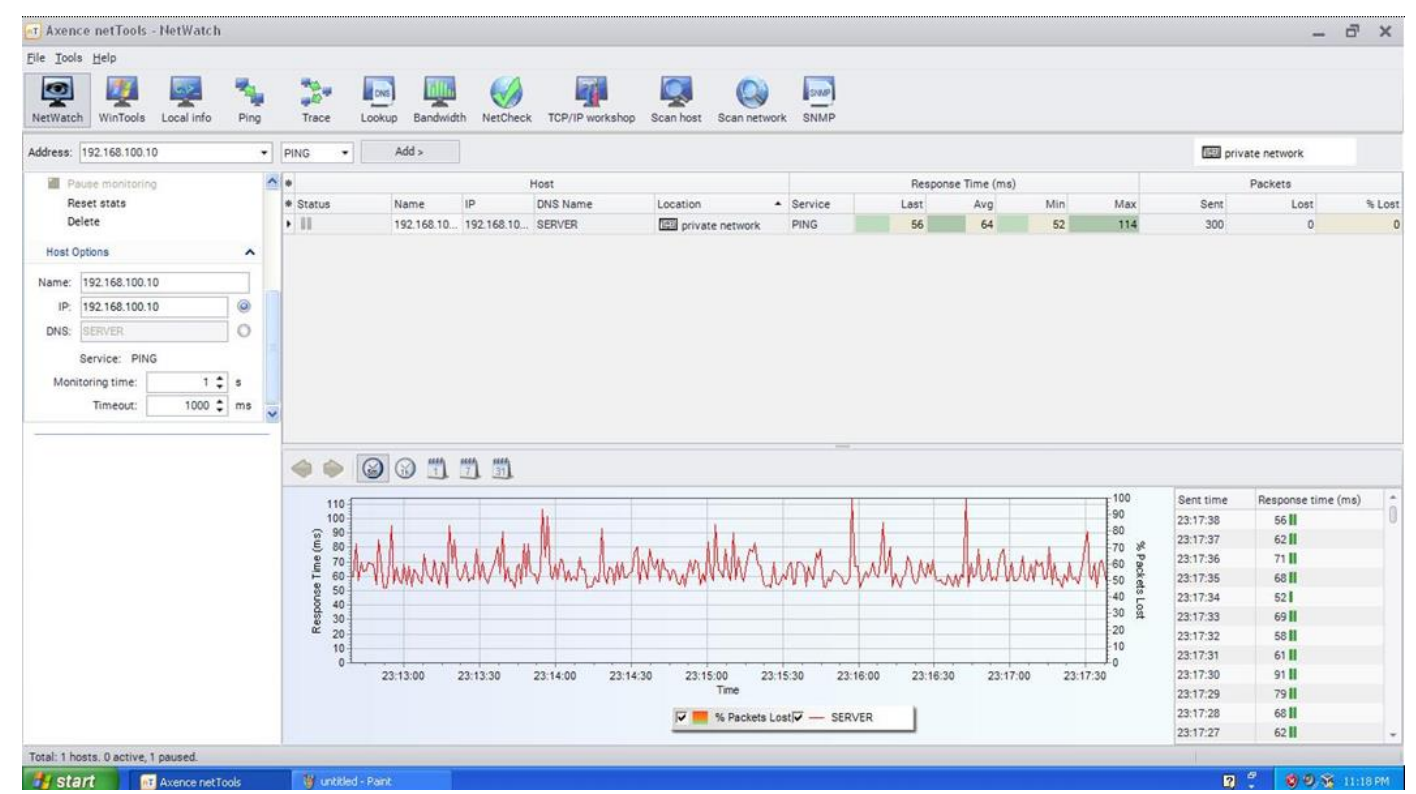

Gambar 4. Sample Pengukuran Quality of Service $(Q o S$

\section{f. Verification and Validation}

Pada tahap ini peneliti melakukan proses verifikasi dan validasi atas apa yang sudah dilakukan pada tahap sebelumnya. Pada tahap ini dimana skenario yang sudah disimulasikan sebelumnya dilakukan ujicoba, hal ini bertujuan apakah jaringan yang sudah disimulasikan sudah berjalan sesuai dengan ketentuan model pada tahap Konseptual, Input dan Output dan Pemodelan.

\section{g. Experimentation}

Pada tahap ini ada 3 skenario yang akan simulasikan dan di ujicobakan, yaitu protokol routing RIPv2 redistribusi EIGRP, RIP Redistribusi IS-IS dan EIGRP redistribusi IS-IS. 12 Host bertujuan membebani lalu lintas jaringan, sedangkan proses pengukuran diambil dari komputer yang berperan sebagai Client. Pada pengujian paket ICMP yang dikirim sebesar 60000 bytes, sedangkan waktu pengiriman paket ICMP dilakukan selama 5 menit pada setiap skenario yang disimulasikan.

\section{HASIL DAN PEMBAHASAN}

Setelah melakukan pengujian sesuai dengan tahapan metodologi penelitian maka dapat dijelaskan hasil dan pembahasan sebagai berikut :

\subsection{Throughput}

Dari hasil pengukuran nilai Throughput RIP Redistribusi EIGRP dan EIGRP Redistribusi IS-IS lebih baik dari RIP Redistribusi IS-IS dengan nilai persentase sama-sama 3\%, sedangkan untuk RIP Redistribusi IS-IS dengan presentase 4\%. Jika dilihat dari sisi jumlah paket yang dikirim dimana RIP redistribusi IS-IS mampu mengirim paket lebih banyak dengan total sent 300, sedangkan yang mampu diterima hanya 287 (96\%) yang total yang dikirim. 
Tabel 4. Perbandingan Nilai Throughput pada redistribusi routing

\begin{tabular}{lcccc}
\hline \multicolumn{1}{c}{ Redistribusi Routing } & $\begin{array}{c}\text { Pakcet Size } \\
\text { ICMP (Bytes) }\end{array}$ & Sent & $\begin{array}{c}\text { Throughput } \\
\text { Received (\%) }\end{array}$ & Lost (\%) \\
\hline RIP Redistribusi EIGRP & 60000 & 296 & $288(97 \%)$ & $8(3 \%)$ \\
RIP Redistribusi IS-IS & 60000 & 300 & $287(96 \%)$ & $13(4 \%)$ \\
EIGRP Redistribusi IS-IS & 60000 & 298 & $289(97 \%)$ & $9(3 \%)$ \\
\hline
\end{tabular}

\subsection{Delay}

Dari hasil pengukuran nilai Delay RIP Redistribusi IS-IS dan EIGRP Redistribusi IS-IS baik dari RIP Redistribusi EIGRP dengan nilai rata-rata 59, sedangkan RIP Redistribusi EIGRP dengan nilai 290. Nilai ini cukup signifikan berbanding jauh jika dibandingkan dengan RIP Redistribusi IS-IS dan EIGRP Redistribusi IS-IS.

Tabel 5. Perbandingan Nilai Delay pada redistribusi routing

\begin{tabular}{lcccc}
\hline \multicolumn{1}{c}{ Redistribusi Routing } & $\begin{array}{c}\text { Pakcet Size } \\
\text { ICMP (Bytes) }\end{array}$ & Min & $\begin{array}{l}\text { Delay (ms) } \\
\text { Maks }\end{array}$ & Rata-rata \\
\hline RIP Redistribusi EIGRP & 60000 & 79 & 391 & 290 \\
RIP Redistribusi IS-IS & 60000 & 41 & 113 & 59 \\
EIGRP Redistribusi IS-IS & 60000 & 42 & 111 & 59 \\
\hline
\end{tabular}

\subsection{Packet Loss}

Dari hasil pengukuran nilai Packet Loss memiliki hasil yang sama dengan masing-masing persentase $0 \%$.

Tabel 6. Perbandingan Nilai Packet Loss pada redistribusi routing

\begin{tabular}{lcccc}
\hline \multicolumn{1}{c}{ Redistribusi Routing } & $\begin{array}{c}\text { Pakcet Size } \\
\text { ICMP (Bytes) }\end{array}$ & Sent & $\begin{array}{c}\text { Packet Loss (ms) } \\
\text { Lost }\end{array}$ & Lost (\%) \\
\hline RIP Redistribusi EIGRP & 60000 & 299 & 0 & 0 \\
RIP Redistribusi IS-IS & 60000 & 303 & 0 & 0 \\
EIGRP Redistribusi IS-IS & 60000 & 300 & 0 & 0 \\
\hline
\end{tabular}

\section{SIMPULAN}

Dari penelitian ini dapat ditarik beberapa kesimpulan sebagai berikut:

a. Untuk nilai Throughput RIP Redistribusi EIGRP dan EIGRP Redistribusi IS-IS berdasarkan hasil pengukuran lebih baik dari RIP Redistribusi IS-IS dengan nilai persentase sama-sama 3\%.

b. Untuk nilai Delay RIP Redistribusi IS-IS dan EIGRP Redistribusi IS-IS berdasarkan hasil pengukuran lebih baik dari Rip Redistribusi EIGRP dengan nilai rata-rata 59, Sementara RIP Redistribusi EIGRP dengan nilai 290. 
c. Untuk nilai Packet Loss berdasarkan hasil pengukuran memeliki hasil yang sama dengan masing-masing persentase $0 \%$.

\section{DAFTAR PUSTAKA}

[1] I. Sofana, "CISCO CCNA \& Jaringan Komputer," in CISCO CCNA \& Jaringan Komputer, 2012.

[2] J. Handoyo, "KAJIAN PENGGUNAAN MIKROTIK ROUTER OSTM SEBAGAI ROUTER PADA JARINGAN KOMPUTER," J. Transform., 2011.

[3] L. S. Moonlight and S. Suhardi, "PENGARUH MODEL JARINGAN TERHADAP OPTIMASI ROUTING OPEN SHORTEST PATH FIRST (OSPF)," Teknologi, 2012.

[4] G. R. J. Allan, Routing Protocols and Concepts, 13th ed. USA: Cisco Press, 2011.

[5] M. C. A. D. N. S. Edi, "Application, Internasional Conference on Information Technology and Engineering," in 1, 5th ed., Palembang: PPP-UBD Press, 2016, p. 180.

[6] A. P. N. Permana and R. Firmansyah, "DISTRIBUSI JARINGAN MENGGUNAKAN ROUTING OSPF DENGAN METODE REDISTRIBUTION," Simetris J. Tek. Mesin, Elektro dan Ilmu Komput., 2018.

[7] A. Y. Nur and M. E. Tozal, "Identifying critical autonomous systems in the Internet," J. Supercomput., 2018.

[8] G. K. Dey, M. M. Ahmed, and K. T. Ahmmed, "Performance analysis and redistribution among RIPv2, EIGRP \& OSPF Routing Protocol," in 1st International Conference on Computer and Information Engineering, ICCIE 2015, 2016.

[9] S. U. Masruroh, F. Robby, and N. Hakiem, "Performance evaluation of routing protocols RIPng, OSPFv3, and EIGRP in an IPv6 network," in 2016 International Conference on Informatics and Computing, ICIC 2016, 2017.

[10] S. U. Masruroh, A. Fiade, M. F. Iman, and Amelia, "Performance evaluation of routing protocol RIPv2, OSPF, EIGRP with BGP," in Proceedings - 2017 International Conference on Innovative and Creative Information Technology: Computational Intelligence and IoT, ICITech 2017, 2018.

[11] Suzanzefi, F. Utami, and Lindawati, "Optimalisasi Load Balancing Dua Isp Untuk Manajemen Bandwidth Berbasis Mikrotik," Pros. Semin. Nas. Multi Disiplin Ilmu Call Pap. SNATI F, 2017.

[12] F. Y. D. Saputro, "ICMP (Internet Control Message Protocol)," 2015. [Online]. Available: https://ilmukomputer.org/wp-content/uploads/2015/01/yamaicmp.pdf. [Accessed: 06-Sep-2019].

[13] H. Fahmi, “Analisis QoS (Quality of Service) Pengukuran Delay, Jitter, Packet Lost Dan Throughput Untuk Mendapatkan Kualitas Kerja Radio Streaming Yang Baik," Teknol. Inf. dan Komun., 2018.

[14] Agusriandi, "ANALISIS DELAY JITTER, THROUGHPUT, DAN PAKET LOST MENGGUNAKAN IPERF3," 2016. [Online]. Available: https://ilmukomputer.org/wp-content/uploads/2017/12/AgusriandiAnalisis.pdf. [Accessed: 09-Sep-2019]. 